\title{
MENINGKATKAN HASIL BELAJAR IPA BIOLOGI MENGGUNAKAN MEDIA PEMBELAJARAN AUDIO VISUAL PADA SISWA KELAS VIIB MTs. MUHAMMDIYAH 1 KOTA SORONG
}

\author{
RISKI SANGAJI ${ }^{1}$, MIFTAHUDIN ${ }^{1,2}$, SUTARDI $^{1,3}$ \\ ${ }^{1}$ Program Studi Pendidikan Biologi STKIP Muhammadiyah Sorong \\ ${ }^{2}$ MTs. Model Sorong \\ ${ }^{3} \mathrm{Lab}$.
}

Email: riskisangaji92@yahoo.com

\begin{abstract}
ABSTRAK
Penelitian ini dilaksanakan dengan tujuan untuk meningkatkan hasil belajar IPA Biologi menggunakan media pembelajaran audio visual pada siswa kelas VIIB MTs. Muhammadiyah 1 Kota Sorong.Rancangan yang diguanakan dalam penelitian adalah rancangan penelitian tindakan yang bertujuan untuk mengetahui peningkatan hasil belajar siswa setelah tindakan.Subjek dalam penelitian ini siswa kelas VIIB MTs. Muhammadiyah 1 Kota Sorong.Teknik pengumpulan data dalam penelitian ini adalah teknik tes dan observasi.Untuk menganalisis data menggunakan rumus kualitatif dan kuantitatif.Berdasarkan hasil penelitian, dapat disimpulkan bahwa penggunaan media pembelajaran audio visual dapat meningkatkan hasil belajar IPA Biologi siswa kelas VIIB MTs. Muhammadiyah 1 Kota Sorong. Hal ini berdasarkan nilai post tes siklus I dan siklus II yang terlihat pada hasil analisis data, dimana pada siklus I dengan siswa tuntas sebanyak 7 siswa $(33,33 \%)$ dari 21 siswa dengan rata-rata nilai 59,52 dan meningkat pada siklus II dengan siswa tuntas sebanyak 18 siswa $(85,71 \%)$ dari 21 siswa dengan rata-rata nilai 78,09. Hal ini berarti penggunaan media pembelajaran audio visual dapat meningkatkan atau mempengaruhi peningkatan hasil belajar siswa.
\end{abstract}

Kata kunci: Hasil Belajar, IPA Biologi, Audio Visual

\section{ABTRACT}

The research was conducted with the aim to improve the learning outcomes of learning Science Biology using audio-visual media at VIIB grade students of MTs. Muhammadiyah 1 Sorong city. The design is primarily used in the study design action research that aims to identify improving student learning outcomes after the action. Subjects in this study VIIB grade students of MTs. Muhammadiyah 1 Sorong city. Data collection techniques in this study are engineering tests and observation. To analyze the data using qualitative and quantitative formula.Based on the results, it can be concluded that the use of audio-visual learning media can improve learning outcomes Science Biology VIIB grade students of MTs. Muhammadiyah 1 Sorong city. It is based on the post-test cycle I and cycle II looks at the results of data analysis, where the students complete the first cycle by as much as 7 students (33.33\%) of the 21 students with an average value of 59.52 and increased in the second cycle with the students completed a total of 18 students $(85.71 \%)$ of 21 students students with an average value of 78.09. This means the use of audio-visual learning media can enhance or influence the improvement of student learning outcomes.

Keywords: Learning Outcomes, Biological Science, Audio Visual.

\section{PENDAHULUAN}

Pendidikan dan pengajaran adalah suatu proses yang sadar terhadap tujuan. Tujuan dapat diartikansebagai suatu usaha untuk memberikan rumusan hasil yang diharapkan siswa setelah melaksanakan pengalaman belajar ${ }^{[1]}$. Tercapai tidaknya tujuan pengajaran salah satunya adalah terlihat dari prestasi belajar yang diraih siswa. Dengan prestasi yang tinggi, para siswa mempunyai indikasi berpengetahuan yang baik.Pendidikan merupakan sesuatu yang penting dalam kehidupan manusia.

Menurut Undang-Undang No. 20 Tahun 2003 pasal 1 ayat (1) tentang Sistem Pendidikan Nasional mengemukakan pengertian pendidikan sebagai berikut: "Pendidikan adalah usaha sadar dan terencana untuk mewujudkan suasana belajar dan proses pembelajaran agar peserta didik secara aktif mengembangkan potensi dirinya untuk memiliki kekuatan spiritual keagamaan, pengendalian diri, kepribadian, kecerdasan, akhlak mulia, serta keterampilan yang diperlukan dirinya, masyarakat, bangsa dan Negara ${ }^{[2]}$

Dalam kurikulum KTSP, menyatakan bahwa Ilmu Pengetahuan Alam (IPA) berhubungan dengan cara mencari tahu tentang alam secara sistematis, sehingga IPA bukan hanya penguasaan kumpulan pengetahuan yang berupa fakta-fakta, konsep-konsep, atau prinsipprinsip saja tetapi juga merupakan suatu proses penemuan yang dikaitkan dengan fenomena alam yang terjadi dalam kehidupan sehari-hari ${ }^{[3]}$

Nilai hasil belajar adalah salah satu indikator yang bisa digunakan untuk mengukur keberhasilan belajar seseorang. Nilai hasil belajar mencerminkan hasil yang dicapai seseorang dari segi kognitif, afektif, maupun psikomotorik $^{[4]}$ 
Dari hasil observasi yang dilakukan, peneliti menemukan beberapa masalah yang terjadi terhadap hasil belajar IPA Biologi pada siswa MTs. Muhammadiyah 1 Kota Sorong. Beberapa masalah tersebut antara lain kurangnya motivasi dan minat belajar siswa, siswa masih banyak meluangkan waktunya untuk bermain dibandingkan belajar, kurangnya kedisiplinan siswa dan metode yang digunakan dalam proses pembelajaran masih banyak menggunakan metode konvensional/ceramah sehingga mengakibatkan hasil belajar siswa juga berkurang. Dari hasil presentase, hasil belajar IPA Biologi pada siswa kelas VIIB MTs. Muhammadiyah 1 Kota Sorong kurang dari $50 \%$ dalam arti hasil belajar tersebut tidak memenuhi nilai standar KKM. Dari masalah tersebut, peneliti mengambil kesimpulan untuk melakukan penelitian dengan judul "Meningkatkan Hasil belajar IPA Biologi menggunakan media pembelajaran audio visual pada siswa kelas VIIB MTs. Muhammadiyah 1 Kota Sorong".

Agar hasil belajar IPA meningkat maka perlu dilakukan tindakan. Tindakan yang dilakukan guru yakni menggunakan media pembelajaran yang dapat membuat anak berbuat sesuatu yang menjadikan dirinya termotivasi untuk melakukan proses belajar IPA $^{[5]}$.

Pemilihan media audio visual di dalam penelitian ini adalah dalam bentuk video pembelajaran dengan menggunakan media komputer/laptop dalam menyajikan video atau animasi-animasi yang ditampilkan dalam bentuk video ataupun powerpoint dalam pembelajaran ini. Dengan media ini diharapkan dapat membantu siswa dalam mempelajari materi secara mandiri. Saat ini media audio visual untuk membantu proses pembelajaran khususnya IPA masih kurang dan belum banyak digunakan.

Dari permasalahan yang diuraikan di atas, maka calon peneliti ingin melakukan penelitian tindakan kelas dengan judul "Meningkatkan Hasil Belajar IPA Biologi Menggunakan Media pembelajaran Audio Visual Pada Siswa kelas VIIB MTs. Muhammadiyah 1 Kota Sorong”.

\section{METODE PENELITIAN}

Penelitian ini dilakukan berdasarkan metode tindakan kelas. Penelitian tindakan kelas atau yang lebih dikenal dengan classroom action research, pada prinsipnya dilakukan untuk mengatasi suatu permasalahan yang terdapat di dalam kelas. Penelitian Tindakan Kelas (PTK) adalah penelitian yang dilakukan oleh guru di kelasnya sendiri melalui refleksi diri dengan tujuan untuk memperbaiki kinerjanya sehingga hasil belajar siswa dapat meningkat ${ }^{[3]}$.

penelitian tindakan (Action Research) mengandung dua kata, yaitu penelitian (Research) dan tindakan (Action). Oleh karena itu kegiatan dalam penelitian ini juga ada dua yaitu, melakukan penelitian dan menguji tindakan ${ }^{[6]}$.
Rancangan siklus penelitian ini menggunakan model Kemmis dan Taggart. Prosedur kerja dalam penelitian tindakan menurut Kemmis \& Taggart meliputi tahap-tahap sebagai berikut : Perencanaan (planning), Tindakan (acting), Observasi (observing) dan Refleksi (reflecting) ${ }^{[4]}$.

Instrument yang digunakan dalam penelitian ini adalah: Lembar Observasi, Butir Soal dan Dokumentasi

Prosedur yang digunakan dalam penelitian ini berbentuk siklus (cycle). Siklus ini tidak hanya berlangsung satu kali tetapi beberapa kali hingga tercapai tujuan yang diharapkan dalam pembelajaran IPA Biologi menggunakan media pembelajaran audio visual di kelas VIIB MTs. Muhammadiyah 1 Kota Sorong. Setiap siklus terdiri dari empat kegiatan pokok yaitu perencanaan (planning), pelaksanaan (action), pengamatan (observation), dan refleksi (reflection).

Penelitian ini menggunakan teknik analisis data secara kualitatif dan kuantitatif. Analisis kualitatif digunakan untuk menganalisis data hasil observasi yang digunakan untuk menjaring aktivitas belajar siswa dalam proses pembelajaran. Sedangkan analisis kuantitatif akan digunakan untuk mendeskripsikan hasil belajar siswa dalam hubungannya dengan penguasaan materi pembelajaran.

Adapun Kriteria ketuntasan keberhasilan siswa dapat dilihat pada tabel berikut:

Tabel 3.1.kriteria ketuntasan keberhasilan siswa

\begin{tabular}{|c|c|}
\hline Presentase & Kriteria \\
\hline $90 \%-100 \%$ & Baik sekali \\
\hline $80 \%-89 \%$ & Baik \\
\hline $70 \%-79 \%$ & Cukup \\
\hline$<70 \%$ & Kurang \\
\hline
\end{tabular}

\section{PEMBAHASAN}

Adapun Hasil Post test Tindakan Pembelajaran Siklus I dijabarkan pada tabel berikut ini :

Tabel 4.4 Rekapitulasi nilai pos test pada siklus I

\begin{tabular}{|c|l|c|c|}
\hline \multirow{2}{*}{ No } & \multirow{2}{*}{ Ketagori } & \multicolumn{2}{|c|}{ Pos test I } \\
\cline { 3 - 4 } & & Jumlah & \% \\
\hline 1 & Tuntas & 7 & 33,33 \\
\hline 2 & Belum Tuntas & 14 & 66,67 \\
\hline & Jumlah & 21 & 100 \\
\hline & Nilai terendah & \multicolumn{2}{|c|}{50} \\
\hline & Nilai tertinggi & \multicolumn{2}{|c|}{95} \\
\hline & Rata - rata & \multicolumn{2}{|c|}{59,52} \\
\hline
\end{tabular}

Dari tabel sebagaimana dijelaskan di atas dapat ditarik kesimpulan bahwa nilai rata-rata hasil belajar pada pelaksanaan perbaikan pembelajaran siklus pertama sebesar 59,52, jumlah siswa yang tuntas belajarnya sebanyak 7 siswa atau sebesar 33,33\%, dan jumlah siswa yang belum tuntas belajarnya sebanyak 14 siswa atau sebesar $66,67 \%$

Hasil observasi pada pelaksanaan perbaikan pembelajaran pada siklus I sebagaimana tabel di bawah ini: 
Tabel 4.5 Rekapitulasi Hasil Observasi Peningkatan Aktivitas Belajar Siswa pada Siklus I

\begin{tabular}{|c|c|c|c|c|c|}
\hline & Indikator & $\begin{array}{c}\text { Jumlah } \\
\text { siswa } \\
\end{array}$ & Skor yang dicapai & $\begin{array}{c}\text { Presentase capaian } \\
\text { indicator }(\%)\end{array}$ & Kategori \\
\hline 1 & Motivasi anak & 21 & 88 & 83,81 & Baik \\
\hline 2 & Kesiapan anak & 21 & 82 & 78,09 & Cukup \\
\hline 3 & Mengungkapkan kembali & 21 & 80 & 76,19 & Cukup \\
\hline 4 & Aktif bertanya & 21 & 82 & 78,09 & Cukup \\
\hline 5 & Prestasi & 21 & 75 & 71,42 & Cukup \\
\hline \multicolumn{4}{|c|}{ Ketuntasan presentase (Rata-rata) } & $\mathbf{7 7 , 5 2}$ & Cukup \\
\hline
\end{tabular}

Dari data hasil pengamatan aktivitas belajar siswa diatas dilihat bahwa ketuntasan presentase aktivitas belajar siswa 77,52\% dengan kategori C (Cukup). melihat hasil diatas maka peneliti bersama-sama dengan guru mitra (observer) sepakat untuk melaksanakan perbaikan pembelajaran pada siklus II dengan harapan pada siklus II ketuntasan presentase aktivitas belajar siswa dapat meningkat sesuai yang diharapkan.

Pada siklus kedua ini dalam tahap pelaksanaan sudah menunjukkan adanya peningkatan hasil belajar siswa. Hal tersebut dapat dilihat pada tabel berikut ini:

Tabel 4.6 Rekapitulasi nilai pos test pada siklus II

\begin{tabular}{|l|l|c|c|}
\hline \multirow{2}{*}{ No } & \multirow{2}{*}{ Ketagori } & \multicolumn{2}{|c|}{ Pos test II } \\
\cline { 3 - 4 } & & Jumlah & \% \\
\hline 1 & Tuntas & 18 & 85,71 \\
\hline 2 & Belum Tuntas & 3 & 14,29 \\
\hline & Jumlah & 21 & 100 \\
\hline & Nilai terendah & \multicolumn{2}{|c|}{55} \\
\hline & Nilai tertinggi & \multicolumn{2}{|c|}{100} \\
\hline & Rata - rata & \multicolumn{2}{|c|}{78,09} \\
\hline
\end{tabular}

Dari tabel tentang rekapitulasi nilai tes formatif pembelajaran IPA Biologi Materi Mendeskripsikan dan mengidentifikasi saling ketergantungan dalam ekosistem di atas dapat diterangkan bahwa nilai ratarata hasil belajar IPA Biologi siswa pada pelaksanaan perbaikan pembelajaran siklus ke-II sebesar 78,09, jumlah siswa yang tuntas belajarnya sebanyak 18 siswa atau sebesar $85,71 \%$, dan masih ada 3 siswa yang belum tuntas belajarnya atau sebesar $14,29 \%$.

Dari penjelasan sebagaimana tersebut di atas dapat disimpulkan bahwa hasil nilai tes formatif mengalami peningkatan pada siklus II, karena pada siklus I siswa tuntas 7 siswa $(33,33 \%)$ meningkat menjadi 18 siswa $(85,71 \%)$ atau meningkat sebanyak 11 siswa $(52,38 \%)$. Melihat hasil di atas maka peneliti menyimpulkan bahwa hasil tes hasil belajar IPA Biologi siswa menunjukkan hasil 78,09. Hal ini menunjukkan bahwa tes hasil belajar sudah memenuhi kriteria keberhasilan karena hasil belajar berada di atas angka kriteria minimal ketuntasan (KKM) sebesar 70, dengan jumlah siswa yang telah tuntas belajarnya sebanyak 18 siswa atau $85,71 \%$.

Hasil observasi pada pelaksanaan perbaikan pembelajaran pada siklus I sebagaimana tabel di bawah ini :

Tabel 4.7 Rekapitulasi Hasil Observasi Peningkatan Aktivitas Belajar Siswa pada Siklus II

\begin{tabular}{|c|c|c|c|c|c|}
\hline $\begin{array}{l}\mathbf{N} \\
\mathbf{0}\end{array}$ & Indikator & $\begin{array}{c}\text { Jumlah } \\
\text { siswa }\end{array}$ & Skor yang dicapai & $\begin{array}{l}\text { Presentase capaian } \\
\text { indicator }(\%)\end{array}$ & Kategori \\
\hline 1 & Motivasi anak & 21 & 96 & 91,42 & Baik Sekali \\
\hline 2 & Kesiapan anak & 21 & 86 & 81,90 & Baik \\
\hline 3 & Mengungkapkan kembali & 21 & 86 & 76,19 & Cukup \\
\hline 4 & Aktif bertanya & 21 & 84 & 80 & Baik \\
\hline 5 & Prestasi & 21 & 88 & 83,80 & Baik \\
\hline \multicolumn{4}{|c|}{ Ketuntasan presentase (Rata-rata) } & 82,66 & Baik \\
\hline \multicolumn{6}{|c|}{ 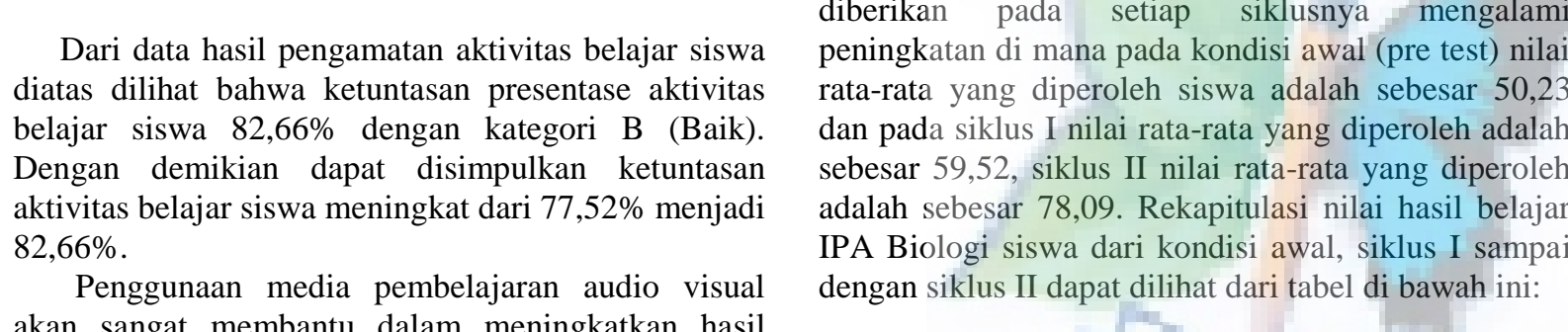 } \\
\hline
\end{tabular}


Tabel 4.8 Nilai Hasil Belajar IPA Biologi Pada Kondisi Awal, Siklus I dan Siklus II

\begin{tabular}{|c|l|c|c|c|c|c|}
\hline \multirow{2}{*}{ No } & \multirow{2}{*}{ Uraian } & \multirow{2}{*}{$\begin{array}{c}\text { Nilai Rata- } \\
\text { rata }\end{array}$} & \multicolumn{2}{|c|}{ Siswa Belum Tuntas } & \multicolumn{2}{c|}{ Siswa Tuntas } \\
\cline { 4 - 7 } & & Frekuensi & \% & Frekuensi & \% \\
\hline 1 & Awal & 50,23 & 16 & 76,19 & 5 & 23,80 \\
\hline 2 & Siklus I & 59,52 & 14 & 66,66 & 7 & 33,33 \\
\hline 3 & Siklus II & 78,09 & 3 & 14,28 & 18 & 85,71 \\
\hline
\end{tabular}

Dari tabel di atas dapat dijelaskan peningkatan nilai hasil belajar siswa pada kondisi awal, siklus I dan siklus II secara terperinci sebagai berikut:

a. Siswa tuntas belajar

1. Pada kondisi awal siswa yang tuntas sebanyak 5 siswa atau $23,80 \%$ dari 21 siswa.

2. Pada siklus I siswa yang tuntas sebanyak 7 siswa atau $33,33 \%$ dari 21 siswa.

3. Pada siklus II siswa yang tuntas sebanyak 18 siswa atau $85,71 \%$ dari 21 siswa.

b. Siswa belum tuntas belajar

1. Pada kondisi awal siswa yang belum tuntas sebanyak 16 siswa atau 76,19\% dari 21 siswa.

2. Pada siklus I siswa yang belum tuntas sebanyak 14 siswa atau $66,66 \%$ dari 21 siswa.

3. Pada siklus II siswa yang belum tuntas sebanyak 3 siswa atau $14,28 \%$ dari 21 siswa.

\section{KESIMPULAN}

Berdasarkan hasil dan pembahasan penelitian yang telah diuraikan pada bab sebelumnya, maka dapat ditarik kesimpulan sebagai berikut:

a. Penggunaan media pembelajaran audio visual dalam pembelajaran IPA Biologi materi saling ketergantungan dalam ekosistem terbukti dapat meningkatkan ketuntasan aktivitas belajar siswa. Hal ini dibuktikan dengan ketuntasan presentase aktivitas belajar yang menunjukkan perolehan $77,52 \%$ pada siklus pertama dan meningkat menjadi $82,66 \%$ pada siklus kedua.

b. Penggunaan media pembelajaran audio visual dalam pembelajaran IPA Biologi materi saling ketergantungan dalam ekosistem terbukti dapat meningkatkan hasil belajar IPA Biologi dan ketuntasan hasil belajar siswa. Hal ini dibuktikan dengan perolehan hasil belajar siswa dari rata-rata pada sebelum perbaikan 50,23 naik menjadi 59,52 pada siklus pertama, dan meningkat menjadi 78,09 pada siklus kedua, dengan tingkat ketuntasan hasil belajar dari 21 siswa yang diperoleh sebanyak 5 atau $23,80 \%$ siswa pada kondisi awal, 7 atau $33,33 \%$ siswa pada siklus pertama dan 18 atau $85,71 \%$ siswa pada siklus kedua.

\section{DAFTAR PUSTAKA}

[1] Pengaruh Motivasi Belajar Siswa Terhadap Prestasi Belajar IPA Di Sekolah Dasar. Hamdu, Ghullam and Agustina, Lisa. TASIKMALAYA : Universitas Pendidikan Indonesia: Jurnal Penelitian Pendidikan, 2011, Vol. 12.

[2] Depdiknas. Buku Guru: Ilmu Pengetahuan Alam SMP Kelas VII. Jakarta : Kemendikbud, 2014.

[3] Penerapan Jigsaw Untuk Meningkatkan Hasil Belajar Siswa Sekolah Dasar. Yulaika, Mei.
Surabaya: E-Jurnal Dinas Pendidikan Kota Surabaya, 2011, Vol. 6.

[4] Peningkatan Hasil Belajar Siswa Dengan Menggunakan Metode Pembelajaran Active Learning Tipe Quiz Team Pada Mata Pelajaran Keterampilan Di SMK Negeri 1 Bogor. Maisaroh and Rostrieningsih. Bogor: Jurnal Ekonomi Dan Pendidikan, 2010, Vol. 8

[5] Penggunaan Education Game Untuk Meningkatkan Hasil Belajar IPA Biologi Konsep Klasifikasi Makhluk Hidup. Rohwati, M. Semarang: FMIPA UNNES Semarang: Jurnal Pendidikan IPA Indonesia, 2012.

[6] Sugiyono. Metode Penelitian Manajemen. Bandung : Alfa beta, 2014. 